\title{
Selected Positive and Negative Ions in the Mass Spectra of the Monohalomethanes
}

\author{
Vernon H. Dibeler and Robert M. Reese
}

\begin{abstract}
Ionization potentials of the molecule ions and appearance potentials of the methyl and halogen positive ions and of the halogen negative ions have been measured for $\mathrm{CH}_{3} \mathrm{~F}, \mathrm{CH}_{3} \mathrm{Cl}$, $\mathrm{CH}_{3} \mathrm{Br}$, and $\mathrm{CH}_{3} \mathrm{I}$ and compared with previously reported spectroscopic and electron-impact data. A value is obtained for the ionization potential of $\mathrm{HF}$ by graphical comparison of the ionization potentials of the hydrogen and methyl halides. Carbon-halogen bond-dissociation energies are computed from appearance potentials of the methyl ion and of the halogen ion. A simple relation between bond-dissociation energy and bond distance is observed for the methyl halides.
\end{abstract}

\section{Introduction}

Electron-impact studies, including the measurement of ionization potentials and appearance potentials of the principal positive ions of most of the monohalomethanes, have been reported by Bauer and Hogness [1] ${ }^{2}$, Morrison and Nicholson [2], McDowell and Cox [3a, b], and Branson and Smith [4]. Spectroseopic ionization potentials have been calculated by Price [5] from Rydberg series in far ultraviolet absorption bands. Only one of these studies has included measurements on methyl fluoride [3b].

In addition to the usual electron-impact measurements of the minimum energy required to form dissociated positive ions of the methyl halides, information concerning possible negative-ion formation and kinetic energy of dissociation products is necessary in order to reduce ambiguities in calsulating bond-dissociation energies. Negative-ion studies are deemed particularly important for molecules containing halogen atoms.

On the basis of measurements of half-widths of ion beams [6], McDowell and coworkers [3a, b, 7] conclude that $\mathrm{CH}_{3}^{+}$ions from methyl chloride, bromide, and iodide are formed without excess kinetic energy. On the other hand, no effort to obtain direct information on the possible role of negative ions in the dissociation of methyl halides has been reported. Accordingly, this paper presents a short study of the appearance potentials and kinetic energy of selected positive and negative ions formed by ionization and by dissociation of the carbonhalogen bond for the complete series of the monohalomethanes.

\section{Experimental Details}

\subsection{Apparatus}

Data were obtained by means of a Consolidated type 21-103 mass spectrometer and a second instrument utilizing type 21-102 components modified

\footnotetext{
1 Presented at the Second Annual Meeting ASTM E-14 Committee on Mass Spectrometry, New Orleans, La., May 1954

2 Figures in brackets indicate the literature references at the end of this paper.
}

for appearance potential measurements and other research. The ionization-emission control of the modified instrument permitted manual control of the filament current supplied by a storage battery. Provision was made to connect the ion-repeller electrodes to a fixed fraction of the ion-accelerating voltage or alternatively to small battery voltages, either positive or negative with respect to the ionization chamber. A decade potentiometer was connected to the output of the ionizing-voltage power supply, permitting the selection of ionizing-voltage increments as small as $0.01 \mathrm{v}$ in the range of 0 to $100 \mathrm{v}$

The 21-103 instrument contains an energy filter at the collector end of the analyser tube that can be connected to the ion-accelerating potential in order to stop ions of zero initial kinetic energy and to allow those with excess energy to reach the collector. The filter can be used to measure kinetic energy, but it is more convenient to measure directly the energy distribution of an ion beam from a voltage scan of a selected ion by using a very low ion-accelerating voltage $(<200 \mathrm{v})$. As the mass scale varies inversely as the ion-accelerating voltage, the resolution in volts is given by the ion-accelerating voltage divided by the mass resolving power. Thus, at an ion-accelerating potential of $200 \mathrm{v}$, a voltage resolution of $0.5 \mathrm{v}$ or less is easily attained.

An improvement of the technique previously described by Mohler, Dibeler, and Reese [8] substitutes for the conventional ion-accelerating voltage power supply, a well-regulated low-voltage power supply shunted with a suitable voltage divider that includes a 10-turn helipot. With the proper mass resolution, manual and automatic adjustment of the scanning voltage by means of the helipot in the vicinity of $200 \mathrm{v}$ permits a precise study and measurement of the $\mathrm{CH}_{3}^{+}$ion peak shape with an estimated best voltage resolution of about $0.4 \mathrm{v}$. Methane introduced simultaneously with the methyl halide provided a fiduciary of $\mathrm{CH}_{3}^{+}$ions, known to be formed without excess kinetic energy [6]. The voltage interval between the resolved zero energy and kineticenergy components of the $\mathrm{CH}_{3}^{+}$ion peak was measured with a sensitive meter by manual adjustment of the scanning voltage divider. 
A separate negative high-voltage power supply and sweep circuit were used to measure negative ion spectra.

The chloro-, bromo-, and iodomethanes were commercial products of high purity, as indicated by mass spectrometric analysis. The fluoromethane was prepared by passing methyl iodide over potassium fluoride in a glass-tube furnace at about $400^{\circ} \mathrm{C}$. The product was obtained in good purity by simple separation of unreacted $\mathrm{CH}_{3} \mathrm{I}$ in cold traps.

\subsection{Determination of Appearance Potentials}

Of the several empirical methods used for determining the minimum energy required to produce positive ions in the mass spectrometer, the one most commonly used is the so-called "vanishingcurrent" method [9a,b,d]. An inherent disadvantage of this method is the frequent opportunity for latitude in judgment concerning the precise point at which the ion current becomes zero.

In describing an alternative, "critical-slope" method, Honig [9c] pointed out that the initial portion of typical ionization-efficiency curves is exponential in character. A semilog plot of ion current versus ionizing voltage obtained with the requisite sensitivity produced an ionization-efficiency curve with a straight-line portion for a range of ion current extending over several orders of magnitude.

A brief note [10] has previously indicated the feasibility of evaluating ionization and appearance potentials of ions without the uncertainty of the extrapolation procedure, merely by measuring the voltage interval between two parallel straight lines plotted on the same normalized scale, one of which corresponds to the ion of unknown critical potential and the other corresponding to an ion of known ionization potential, such as argon or krypton. Normalization of the two curves is accomplished by adjusting partial pressures of the gases so as to give approximately equal ion current for the two ions at electron energies of $70 \mathrm{v}$. It is an experimental fact that for positive ions produced by ionization and dissociation processes of comparable probability and similar character, the conditions necessary to obtain parallel lines are not critical for molecule ions and many dissociative ions of a number of compounds studied so far. This method has been used for evaluating the appearance potentials of the positive ions in the present paper.

Ionization-efficiency curves of the negative halogen ions were plotted satisfactorily on the more conventional linear scale, although accurate calibration of the ionizing-voltage scale remained an acute problem, particularly for electron-capture processes. The $\mathrm{O}^{-}$ion from $\mathrm{CO}$ (A.P. $=9.6 \mathrm{ev}$ ) [11] provided a reasonably satisfactory calibration for the ion-pai. processes. However, the appearance potential of the $\mathrm{F}^{-}$ion from methyl fluoride apparently was more reproducible and served as a calibration for the measurement of the $\mathrm{Cl}^{-}$ion in methyl chloride.

\section{Results}

The initial exponential portions of the ionizationefficiency curves of the $\mathrm{CH}_{3} \mathrm{I}^{+}, \mathrm{CH}_{3}^{+}$, and $\mathrm{I}^{+}$ions, together with those of the calibrating gases, argon and krypton, are shown in the semilog plot of figure 1. The uncorrected ionizing voltage is plotted on the abscissa; the ion current in arbitrary units, on the ordinate. The curves are remarkably parallel, and the indicated voltage intervals between argon and krypton and between argon and $\mathrm{CH}_{3} \mathrm{I}^{+}$are in good agreement with the intervals between the spectroscopic ionization potentials of these molecules. Thus, from the spectroscopic value, $I^{Z}(\mathrm{~A})=$ $15.76 \mathrm{ev}$ [12], the electron-impact ionization potential of krypton is $14.0_{1} \mathrm{ev}$ and that of $\mathrm{CH}_{3} \mathrm{I}$ is $9.5_{5} \mathrm{ev}$. The spectroscopic values for the first ionization potentials of krypton and methyl iodide are 13.996 [12] and 9.49 [5], respectively. The appearance potentials of the $\mathrm{CH}_{3}^{+}$and the $\mathrm{I}^{+}$ions are evaluated in the same way.

The curves in figure 1 are representative of the curves for the molecule ions and halogen positive ions of all of the methyl halides, except methyl fluorides and of the methyl ions of the iodo- and bromomethanes. A different type of curve is illustrated by the initial portion of the methyl ion curve from methyl chloride shown in figure 2 , together with the calibrating gas, argon. The deviation in the

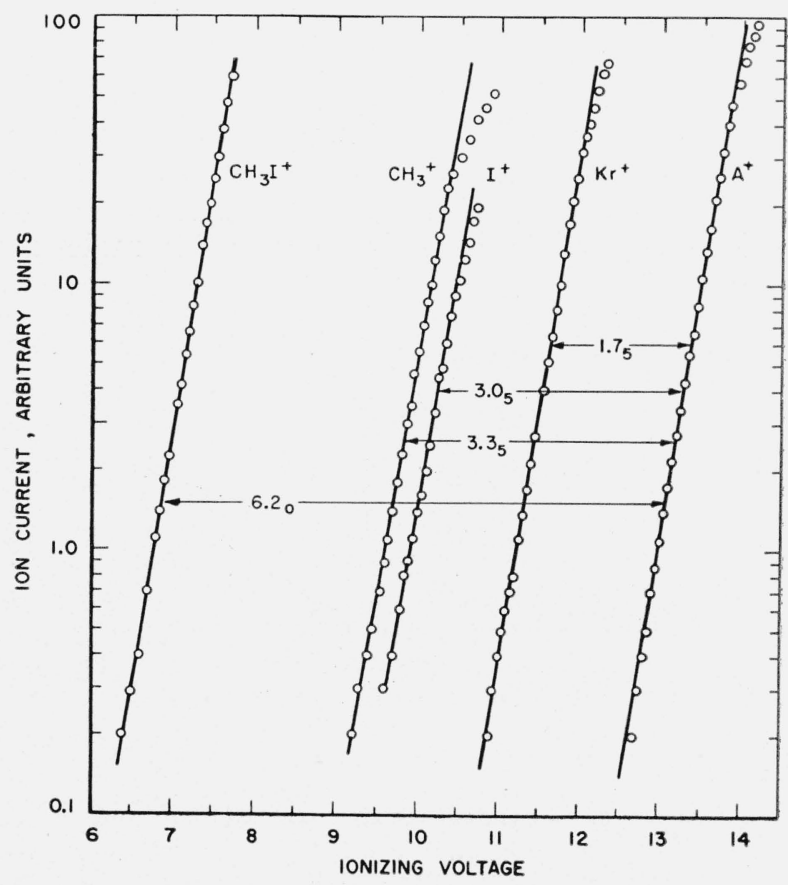

FIGURE 1. Initial exponential portions of the ionization-effciency curves for ions of methyl iodide and of the calibration gases, argon and krypton.

The voltage scale is uncorrected. 


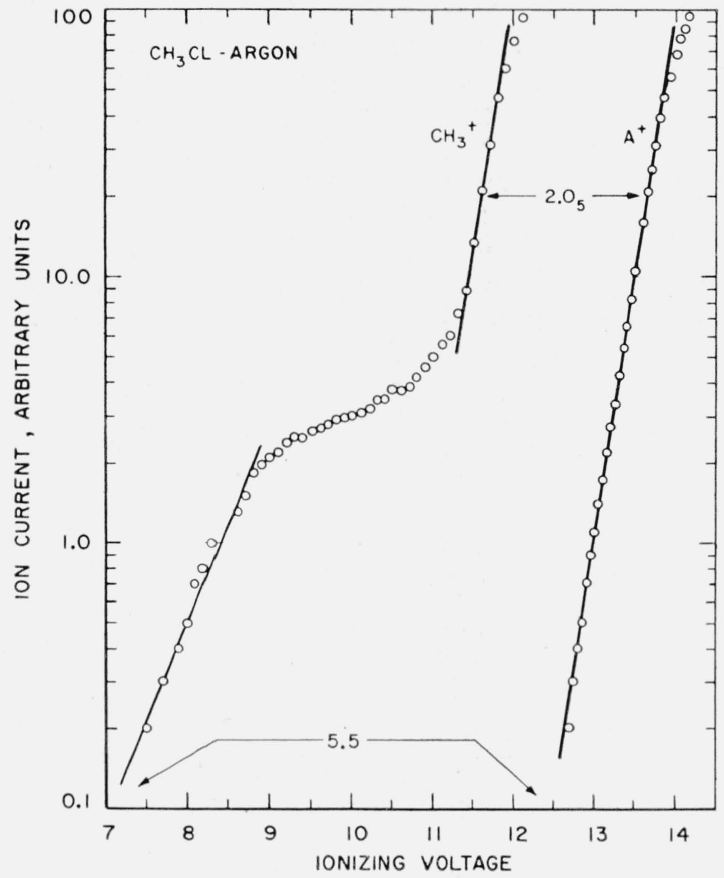

Figure 2. Initial exponential portion of the $\mathrm{CH}_{3}^{+}$ion from methyl chloride compared with that of the calibrating gas, argon.

The voltage scale is uncorrected.

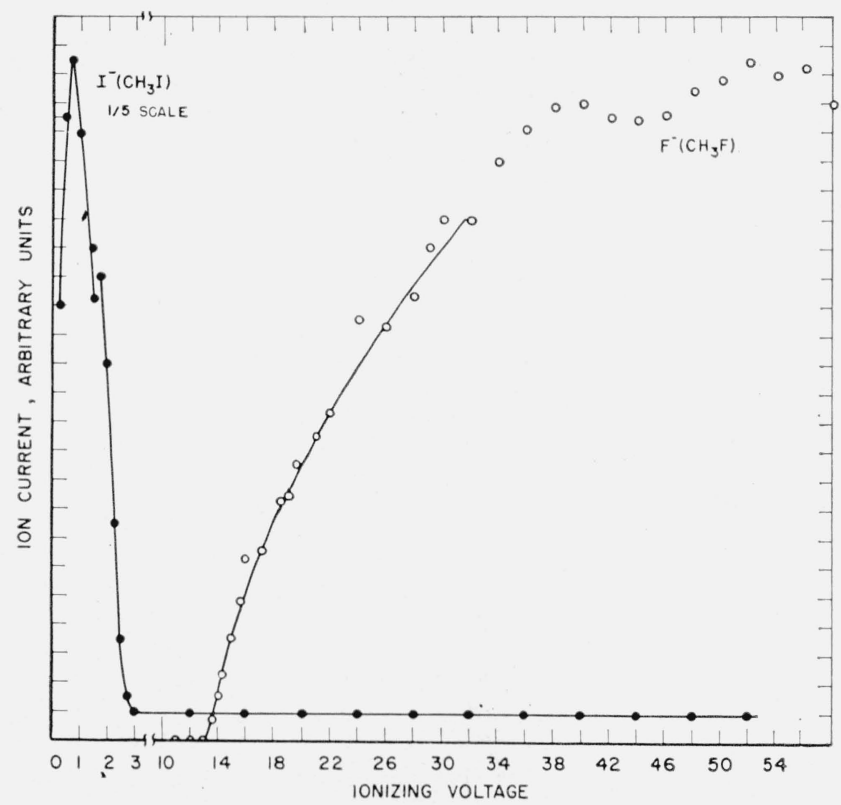

Figure 3. Ionization-efficiency curves of the $\mathrm{F}^{-}$and $\mathrm{I}^{-}$ions from $\mathrm{CH}_{3} \mathrm{~F}$ and $\mathrm{CH}_{3} \mathrm{I}$, respectively.

The voltage scale is uncorrected.

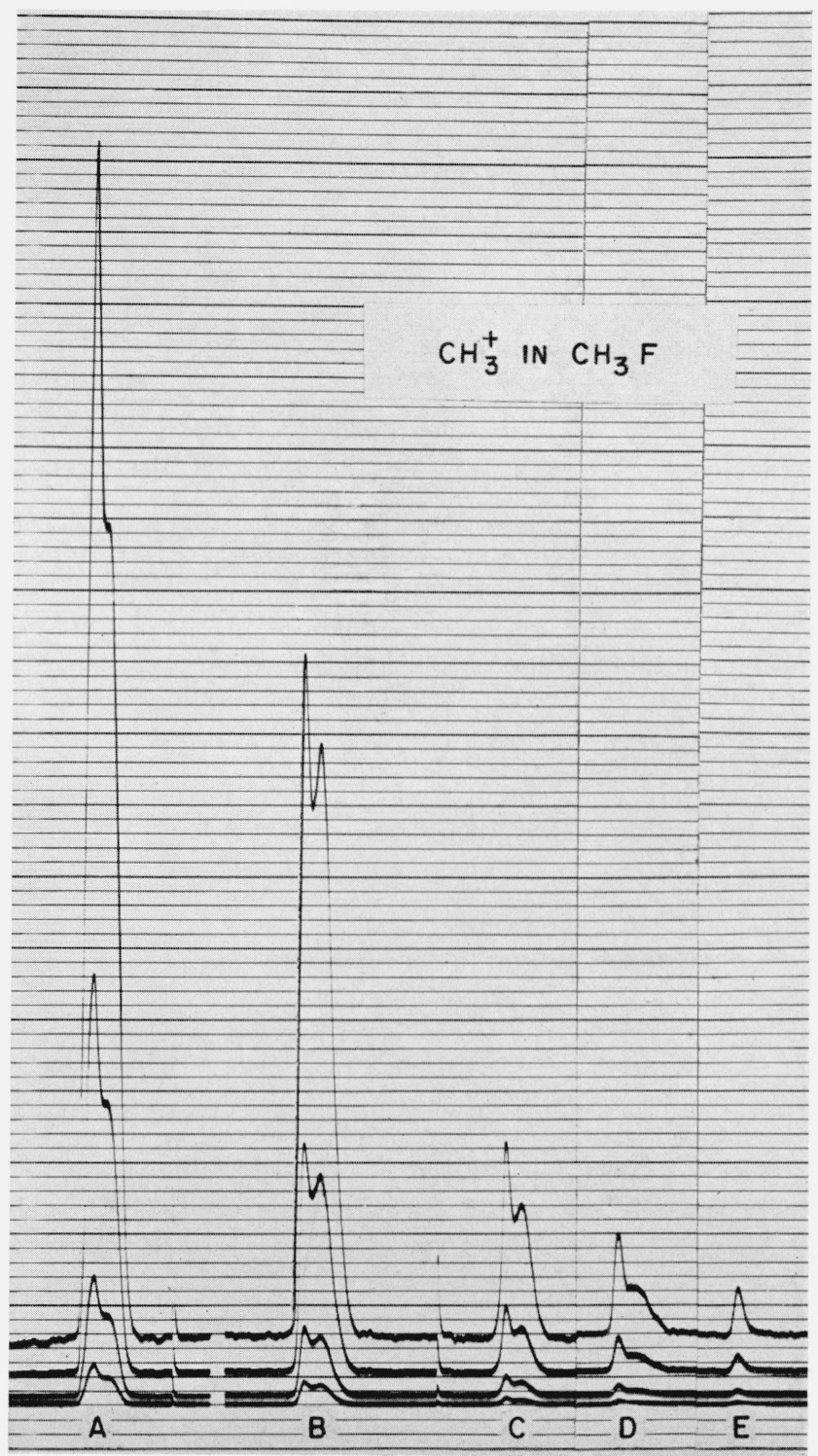

Figure 4. Separation of the thermal- and kinetic-energy components of the $\mathrm{CH}_{3}^{+}$ion of methyl fluoride and the effect of ionizing voltage on the separate peaks. 
slope of the $\mathrm{CH}_{3}^{+}$curve is interpreted as indicating two ionization processes; i. e.,

$$
\begin{aligned}
& \mathrm{CH}_{3} \mathrm{Cl}+\mathrm{e} \rightarrow \mathrm{CH}_{3}^{+}+\mathrm{Cl}+2 \mathrm{e} \\
& \mathrm{CH}_{3} \mathrm{Cl}+\mathrm{e} \rightarrow \mathrm{CH}_{3}^{+}+\mathrm{Cl}^{-}+\mathrm{e}
\end{aligned}
$$

This is supported by the fact that the difference in the two voltage intervals between the $\mathrm{CH}_{3}^{+}$and $\mathrm{A}^{+}$ curves corresponding to processes (1) and (2) (3.5 v) approximates the electron affinity of the chlorine atom $\left(3.7_{5} \mathrm{v}\right)[13$.

The ionization efficiency curve for the $\mathrm{CH}_{3}^{+}$ion of methyl fluoride resembles that of the methyl ion from $\mathrm{CH}_{3} \mathrm{Cl}$. One appearance potential is about $1 \mathrm{v}$ above the ionization potential of argon and one about $2.5 \mathrm{v}$ below, with evidence of an intermediate appearance potential. The voltage interval between the extreme appearance potentials is roughly $3.5 \mathrm{~V}$, and the electron affinity of the fluorine atom is 3.6 $\mathrm{v}[13]$.

The $\mathrm{F}^{+}$ion curve was very difficult to evaluate. The observed appearance potential was about $23 \mathrm{v}$.

The ionization-efficiency curves of the negative halogen ions are represented by the two curves shown in figure 3. The voltage scale is uncorrected. The $\mathrm{I}^{-}$and $\mathrm{Br}^{-}$ions are both formed by dissociative electron capture, with an appearance potential very near to zero volts, as illustrated in the figure. There was no evidence of other ionization processes with electron energies extending to $90 \mathrm{v}$. The very gradual increase in the small ion current observed at higher voltages is not deemed significant.

On the other hand, the $\mathrm{Cl}^{-}$and $\mathrm{F}^{-}$ions are formed by ion-pair processes only, with no evidence of an electron-capture process. As indicated, the appearance potential of the ion-pair process is a relatively simple one to evaluate compared to the capture process. The general features of the fine structure in the ionization-efficiency curves of the negative ions are quite reproducible, but are of unexplained origin at present.

Evidence of methyl ions formed with kinetic energy was found only in methyl fluoride. From the shape of the $\mathrm{CH}_{3}^{+}$peak recorded at low ion-accelerating voltage, the excess kinetic energy of methyl ions in $\mathrm{CH}_{3} \mathrm{Cl}$ is estimated to be less than $0.5 \mathrm{v}$, and in the other methyl halides is estimated to be less than 0.2 v. Figure 4 is a composite record of the $\mathrm{CH}_{3}^{+}$ion peak of methyl fluoride partially separated into a narrow and a wide portion when measured at $200-\mathrm{v}$ ion-accelerating voltage. Four galvanometers with different sensitivities record each peak, resulting in the four traces shown. From figure 4, A, the apparent abundance of ions with excess kinetic energy is about 71 percent of the abundance of ions with thermal energy. It is well known, however, that ions with initial kinetic energy are collected with low efficiency, and the apparent relative abundance of the ions having excess kinetic energy will decrease rapidly as the ion-accelerating voltage is decreased.

\begin{tabular}{|c|c|c|c|c|}
\hline Ion & Abundance & $\begin{array}{c}\text { Appearance } \\
\text { potential }\end{array}$ & Remarks & Comparison values \\
\hline \multicolumn{5}{|c|}{$\mathrm{CH}_{3} \mathrm{~F}$} \\
\hline $\begin{array}{l}\mathrm{CH}_{3} \mathrm{~F}_{+}^{+} \ldots \ldots \\
\mathrm{FH}_{3}^{+}+\ldots \ldots\end{array}$ & $\begin{array}{r}\% \\
100 \\
98 \\
1.5 \\
\sim 0.6\end{array}$ & $\left\{\begin{array}{l}12.6 \pm 0.1 \\
16.5 \pm 0.5 \\
16.3 \pm 0.3 \\
14.7 \pm 0.3 \\
12.7 \pm 0.5 \\
23.0 \pm 0.5 \\
12.4 \pm 0.5\end{array}\right.$ & $\begin{array}{l}\text { Ionization potential } \\
\text { "Second" appearance potential, } \mathrm{V}_{\mathrm{IA}}=2,500 \mathrm{~V} \text {. } \\
\text { "Kinetic-energy" ion, VIA }=200 \mathrm{~V} \text {. } \\
\text { "Thermal-energy" ion, VIA }=200 \mathrm{v} \\
\text { Ion-pair process. "First" appearance potential, VIA }=2,500 \mathrm{~V} \text {. } \\
\text { Principal process for } \mathrm{F}+\text { ion. } \\
\text { Ion-pair process. }\end{array}$ & $\begin{array}{l}12.84 \pm 0.03[3 \mathrm{~b}] \\
14.6[19]\end{array}$ \\
\hline \multicolumn{5}{|c|}{$\mathrm{CH}_{3} \mathrm{Cl}$} \\
\hline $\begin{array}{l}\mathrm{CH}_{3} \mathrm{Cl}^{+}+\ldots \\
\mathrm{CH}_{3}^{+} \\
\mathrm{Cl}^{+}+\ldots+\ldots \\
\mathrm{Cl}^{-}\end{array}$ & $\begin{array}{r}100 \\
85 \\
\quad 4 \\
\sim 0.1\end{array}$ & $\left\{\begin{array}{l}11.3 \pm 0.1 \\
13.7 \pm 0.2 \\
10.2 \pm 0.5 \\
16.5 \pm 0.5 \\
10 \pm 1\end{array}\right.$ & $\begin{array}{l}\text { Ionization potential } \\
\text { Kinetic energy }<0.5 \mathrm{v} \\
\text { Ion-pair process. }\end{array}$ & $\begin{array}{l}11.17[5], 11.25[5], 11.3[4] \\
13.44[19], 13.5[4] \\
16.6[4]\end{array}$ \\
\hline \multicolumn{5}{|c|}{$\mathrm{CH}_{3} \mathrm{Br}$} \\
\hline $\begin{array}{l}\mathrm{CH}_{3} \mathrm{Br}^{+} \\
\mathrm{CH}_{3}^{+} \\
\mathrm{Br}^{+} \\
\mathrm{Br}^{-}\end{array}$ & $\begin{array}{r}96 \\
100 \\
8 \\
\sim 1\end{array}$ & $\begin{aligned} & 10.5 \pm 0.1 \\
& 12.9 \pm 0.1 \\
& 14.8 \pm 0.3 \\
& 0\end{aligned}$ & $\begin{array}{l}\text { Ionization potential } \\
\text { Kinetic energy }<0.2 \mathrm{~V}\end{array}$ & $\begin{array}{l}10.49[5], 10.80[5], 10.5[4] \\
12.83[19], 13.2[4] \\
15.0[4]\end{array}$ \\
\hline \multicolumn{5}{|c|}{$\mathrm{CH}_{3} \mathrm{I}$} \\
\hline $\begin{array}{l}\mathrm{CH}_{3} \mathrm{I}^{+} \\
\mathrm{I}_{3}^{+}+\ldots \ldots \\
\mathrm{I}^{+}\end{array}$ & $\begin{array}{r}100 \\
13 \\
38 \\
\sim 2\end{array}$ & $\begin{array}{r}9.5 \pm \pm 0.1 \\
12.4 \pm 0.2 \\
12.7 \pm 0.2 \\
0\end{array}$ & $\begin{array}{l}\text { Ionization potential } \\
\text { Kinetic energy }<0.2 \mathrm{v} \\
\text { Electron capture. }\end{array}$ & $\begin{array}{l}9.49[5], 10.11[5], 9.6[4] \\
12.15[19], 12.4[4], 12.36[3 \mathrm{a}] \\
12.88[19], 12.9[4]\end{array}$ \\
\hline
\end{tabular}

TABLE 1. Relative abundances and appearance potentials of selected methyl halide ions 
In figure 4, A, the energy filter is grounded, and ions with thermal and excess kinetic energy reach the collector; in figure 4, B, the energy filter is connected to the ion-accelerating voltage supply and adjusted to give nearly equal abundances of thermalkinetic-energy peaks. Under the same filter conditions, figures $4, \mathrm{C}, \mathrm{D}$, and $\mathrm{E}$, show the effect on the separate peaks of lowering the uncorrected ionizing voltage to 20,17 , and $15 \mathrm{~V}$, respectively. A plot of peak height versus ionizing voltage taken at $1-v$ intervals indicates the appearance potential of the ions with excess kinetic energy to be about $16.3 \mathrm{v}$, whereas that of the ions with thermal energy is about $14.7 \mathrm{v}$.

With the energy filter connected to high voltage and adjusted to give nearly equal heights of the thermal- and kinetic-energy peaks (fig. 4, B), the ion-accelerating voltage interval between the maxima of the two peaks was found to be approximately $0.7 \mathrm{v}$. Thus, the total kinetic energy of the dissociation process, calculated from the voltage interval between the maxima of the kinetic and thermal-energy peaks and consideration of the conservation of momentum, is $1.3 \mathrm{v}$. The difference of $1.6 \mathrm{v}$ between the appearance potentials is equal to this within the experimental uncertainty.

There was no evidence of the heterogeneous nature of the $\mathrm{CH}_{3}^{+}$ion peak with an ion-accelerating voltage of $2,500 \mathrm{v}$. The observed "second" appearance potential of the $\mathrm{CH}_{3}^{+}$ion, measured at an ionaccelerating voltage of $2,500 \mathrm{v}$, apparently corresponds to that of the methyl ion formed with excess kinetic energy.

A summary of the appearance potentials and related data for selected ions of the methyl halides is given in table 1 . Columns 1 and 2 list, respectively, the selected methyl halide ions, and the abundance relative to the most abundant ion (equals 100) at a nominal electron energy of $70 \mathrm{v}$. There are two exceptions: The abundances of the $\mathrm{Br}^{-}$and the $\mathrm{I}^{-}$ions are measured at electron energies of about $0.5 \mathrm{v}$ (uncorrected), but are relative to the most abundant positive ion measured at $70 \mathrm{v}$. Column 3 gives the observed appearance potentials and the experimental errors estimated from the reproducibility of the measurements. The absolute value of an appearance potential less than $2 \mathrm{v}$ is uncertain to the extent of at least $1 \mathrm{v}$. Explanatory remarks appear in column 4. Column 5 gives comparison values from the literature.

\section{Calculation of Bond-Dissociation Energies}

The minimum energy (appearance potential) required to form positive methyl ions and halogen atoms from the methyl halides is given by the relation

$$
A\left(\mathrm{CH}_{3}^{+}\right)=D\left(\mathrm{CH}_{3}-X\right)+I\left(\mathrm{CH}_{3}\right)+E_{k}^{,}
$$

where $D\left(\mathrm{CH}_{3}-X\right)$ is the carbon-halogen bond-dis- sociation energy, $I\left(\mathrm{CH}_{3}\right)$ is the ionization potential of the methyl radical, and $E_{k}$ is the total kinetic energy of the dissociation products. Thus, in the case of methyl fluoride, from table $1, A\left(\mathrm{CH}_{3}^{+}\right)=$ $16.5 \mathrm{v}$. Substituting into the above relation this value and the values for the ionization potential of the methyl radical $(9.95 \mathrm{v})$ [14] and the total kinetic energy (1.6 v) from the observed difference in appearance potentials of the resolved methyl ions gives a bond-dissociation energy of $4.9 \mathrm{ev}$. In the case of the thermal-energy ions measured, as illustrated in figure $4, A\left(\mathrm{CH}_{3}^{+}\right)=14.7$ v. Subtracting the ionization potential of the methyl radical gives directly the $\mathrm{C}-\mathrm{F}$ bond-dissociation energy of $4.7 \mathrm{ev}$. For reasons apparent in the following pages, this value is preferred among those appearing in column 2, table 2 .

TABLE 2. Bond-dissociation energies of methyl halides

\begin{tabular}{|c|c|c|c|c|c|}
\hline \multirow{2}{*}{ Bond } & \multicolumn{2}{|c|}{$\begin{array}{l}\text { Dissociation energy (ev) from } \\
\text { observed valiaes of-- }\end{array}$} & \multicolumn{3}{|c|}{ Literature references- } \\
\hline & $A\left(\mathrm{CH}_{3}^{+}\right)$ & $A\left(\mathrm{X}^{+}\right)$ & [19] & [4] & [22] \\
\hline $\mathrm{CH}_{3}-\mathrm{F}_{-}$ & $\left\{\begin{array}{r}4.7 \pm 0.2 \\
\text { a4. } 9 \pm 0.2 \\
\text { b4. } 7 \pm 0.3\end{array}\right.$ & $5.6 \pm 0.5$ & 4. 6 & ... & $\ldots$ \\
\hline $\mathrm{CH}_{3}-\mathrm{Cl}$ & $\left\{\begin{array}{r}3.7 \pm 0.2 \\
\text { c4. } 0 \pm 0.5\end{array}\right.$ & $3.5 \pm 0.5$ & 3.5 & 3.4 & 3.5 \\
\hline $\mathrm{CH}_{3}-\mathrm{Br}$ & 2. $9 \pm 0.1$ & $3.0 \pm 0.3$ & 2. 9 & 3.2 & 2. 9 \\
\hline $\mathrm{CH}_{3}-\mathrm{I}$ & 2. $4 \pm 0.2$ & $2.3 \pm 0.2$ & 2. 2 & 2. 3 & 2. 4 \\
\hline
\end{tabular}

a Dissociation process in which kinetic energy equals $1.6 \mathrm{~V}$

$\mathrm{b}$ Ion-pair process in which kinetic energy equals $1.6 \mathrm{v}$.

c Ion-pair process.

When negative halogen and positive methyl ions are formed simultaneously, the appearance potential of either ion is given by the relation

$$
A\left(\mathrm{CH}_{3}^{+}, X^{-}\right)=D\left(\mathrm{CH}_{3}-X\right)+I\left(\mathrm{CH}_{3}\right)-E_{a}(X)+E_{k},
$$

where $E_{a}(X)$ is the electron affinity of the halogen atom. The observed appearance potentials of the ion-pair process, $A\left(\mathrm{CH}_{3}^{+}\right)=12.7 \mathrm{v}$ and $A\left(\mathrm{~F}^{-}\right)=$ $12.4 \mathrm{v}$, again indicate a $\mathrm{C}-\mathrm{F}$ bond-dissociation energy of about $4.7 \mathrm{ev}$.

The bond-dissociation energy in methyl chloride can be calculated similarly by using the ion-pair appearance potential. However, the higher value obtained by the simple formation of $\mathrm{CH}_{3}^{+}, \mathrm{Cl}$, and a free electron is considered the more precise. Therefore, as excess kinetic energy of the methyl ion is apparently negligible, the carbon-halogen bonddissociation energy in the chloride, bromide, and iodide molecules is computed simply by subtracting the ionization potential of the methyl radical from the appearance potential of the methyl ion. Table 2 , column 2, summarizes the bond-dissociation energies thus obtained. Similar calculations from the appearance potentials of the halogen ions (column 3, table 2) give satisfactory agreement within the estimated uncertainties. 


\section{Discussion}

\subsection{Molecule Ions}

The ionization potentials of chloro-, bromo-, and iodomethane given in table 1 are in good agreement with the electron-impact values reported by Branson and Smith [4] and, except for methyl chloride, with the lower of the doublet spectroscopic values reported by Price [5]. No spectroscopic ionization potential of $\mathrm{CH}_{3} \mathrm{~F}$ has been published. The disagreement between the ionization potential of methyl fluoride reported here and that reported by McDowell and Cox [3b] is slightly greater than the sum of the estimated experimental errors in both researches.

The existence in the spectra of the methyl halides of two electronic series of absorption bands in the far ultraviolet corresponding to two ionization potentials was predicted by Mulliken [15] and independently observed by Price [5]. Although the voltage interval between the doublet spectroscopic ionization potentials is greater than $0.6 \mathrm{v}$ for methyl iodide (and less for the others), no indication of a break was observed in the ionization-efficiency curve of the $\mathrm{CH}_{3} \mathrm{I}^{+}$ion.

If the ionization potentials of the methyl halides from table 1 and of methane [4] are plotted against a scale proportional to the total quantum number of $\mathrm{H}$, and the halogen atoms, the empirical linear relation shown in the lower curve of figure 5 is obtained. As the ionization of the methyl halides (with the exception of $\mathrm{CH}_{3} \mathrm{~F}$ [3b]) occurs by the removal of one of the nonbonding " $p \pi$ " electrons localized on the halogen atom [15], it is somewhat interesting that the ionization potential of methane also falls on the same curve. A similar linear relation is expected to hold for the ionization potentials of the hydrogen halides. ${ }^{3} \quad$ That this is apparently the case, is shown by the spectroscopic data [17] plotted as the upper curve of figure 5 . The assumption that the ioniza-

3 Teegan and Walsh [16] note empirical linear relationships between the ionization potentials of inert gases and of a number of isoelectronic atoms, ions, and diatomic molecules, including the hydrogen halides.

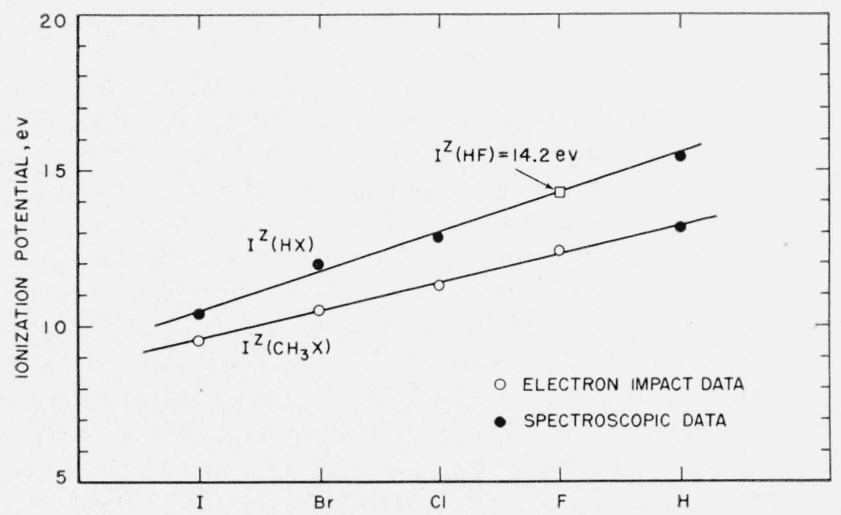

Figure 5. Spectroscopic and electron-impact values for the ionization potentials of the hydrogen and methyl halides plotted against a scale proportional to the total quantum numbers of the hydrogen and halogen atoms. tion potential of $\mathrm{HF}$ falls in line with the hydrogen halides and hydrogen, as $\mathrm{CH}_{3} \mathrm{~F}$ does with the methyl halides and methane, supports the indicated interpolation and the resultant value of $I^{\mathrm{z}}(\mathrm{HF})=14.2 \mathrm{v}$. This is in agreement with the lowest of several values of the ionization potential; namely, 14.02, 15.7, and $18.04 \mathrm{v}$, estimated at various times by means of quantum mechanical and thermodyamic calculation [18]. A higher value of about $18 \mathrm{v}$ is estimated from figure 1 of the paper by Teegan and Walsh [16].

\subsection{Dissociative Ions}

The methyl ions are relatively abundant in all of the spectra, except that of methyl iodide, and the reproducibility of the appearance potential measurements is comparable with that of the ionization potential. As indicated in table 1, there is good agreement with previously published values for the chloro-, bromo-, and iodocompounds, although the second appearance potential associated with the ion-pair formation of the methyl ion in methyl chloride is previously unreported. Branson and Smith [4] did not search for negative ions, and their use of the linear extrapolation method for correcting the voltage scale evidently did not reveal the ionpair process in methyl chloride. This is not surprising in view of the relative abundance of the $\mathrm{Cl}^{-}$ion shown in table 1 . However, this fact, together with the existence of $\mathrm{Br}^{-}$and $\mathrm{I}^{-}$ions formed by electron capture, does not affect their conclusions concerning the carbon-halogen bond-dissociation energies.

The production of $\mathrm{CH}_{3}^{+}$ions in methyl fluoride is complicated not only by the simultaneous formation of $\mathrm{F}^{-}$ions, but also by the apparent existence of dissociation processes resulting in methyl ions with thermal energy and methyl ions with excess kinetic energy. An accurate measure of the relative probabilities of thermal- and kinetic-energy processes is very difficult in view of the magnitude of the effect of the ion-accelerating voltage on the efficiency of collecting ions with excess kinetic energy. That the ions with excess kinetic energy are in great abundance at $2,500 \mathrm{v}$, however, is suggested by the fact that a several-fold increase in the apparent abundance of such ions relative to thermal-energy ions has been observed by increasing the ion-accelerating voltage from 150 to $500 \mathrm{v}$ [8]. This indicates a high probability for the process producing fragments with kinetic energy.

In agreement with previous research [3,7], no evidence was found for methyl ions with excess kinetic energy in the chloro-, bromo-, or iodomethanes.

For methyl fluoride, Lossing [19] has reported a measurement of $A\left(\mathrm{CH}_{3}^{+}\right)=14.6 \mathrm{v}$. In the present research, measurements made at an ion-accelerating voltage of $2,500 \mathrm{v}$ gave no clearly defined break in the exponential portion of the $\mathrm{CH}_{3}^{+}$ionization-efficiency curve corresponding to ions with this critical potential. However, good agreement with the value was obtained for the appearance potential of the thermal- 
energy ions $(14.7 \mathrm{v})$ when these were resolved from the ions with excess kinetic energy $($ A.P. $=16.3 \mathrm{v})$. Unfortunately, the sensitivity of the measurement was considerably reduced at the necessarily low ionaccelerating voltage $(200 \mathrm{v})$. Failure to observe the lowest appearance potential associated with ion-pair formation in this experiment was purely a matter of sensitivity. (The observed abundance of $\mathrm{F}^{-}$relative to $\mathrm{CH}_{3}^{+}$is $0.6 \%$.) The experiments give no direct evidence as to whether there is excess kinetic energy associated with ion-pair production.

The agreement of the $\mathrm{C}-\mathrm{F}$ bond-dissociation energy obtained in this research (see table 2) with that reported by Lossing [19] is interesting, but may be fortuitous. Although the existence of three dissociation processes seems fairly well established, the evaluation of three appearance potentials in the range of a few volts is very difficult.

As the relative abundance of the halogen ions decreases markedly from the iodide to the fluoride, the precision of measurement of the appearance potential of these ions also decreases. The observation of the appearance potential of $23 \mathrm{v}$ for the $\mathrm{F}^{+}$ion is not very precise, but apparently is well established by several measurements. An additional experimental uncertainty results from the undesirably large $(\sim 7 \mathrm{v})$ voltage interval between the appearance potential of $\mathrm{F}^{+}$and the ionization potential of the calibrating gas (argon). A more detailed study of these observations is included in research currently in progress on the ionization and dissociation of the complete series of fluoromethanes.

As demonstrated in table 2 of this research and as previously observed by Branson and Smith [4], satisfactory agreement is obtained for the chloro-, bromo-, and iodomethanes between the carbonhalogen bond-dissociation energy calculated from the appearance potential of the methyl ions and that calculated from the halogen ion. In disagreement with Branson and Smith, however, the present authors conclude that within the experimental uncertainties for these molecules, there is no evidence for the applicability of a rule proposed by Stevenson ${ }^{4}$ and so successfully applied by him to the energetics of the dissociation of hydrocarbons by electron impact [20].

The concept of the relation between bond distance and bond-dissociation energy is well known and often demonstrated to be other than a simple one. However, a simple relation between bond distance and carbon-halogen bond-dissociation energy computed from the methyl ion appearance potential is indicated in figure 6. The dissociation energy for the first $C-H$ bond in methane [20] is included for comparison. Its position on the energy scale relative to the methyl halides is consistent with the fact that hydrogen atoms will not react with $\mathrm{CH}_{3} \mathrm{~F}$, but do react with increasing ease from $\mathrm{CH}_{3} \mathrm{Cl}$ to $\mathrm{CH}_{3} \mathrm{I}$ [21].

The uncertainty in the measurement of the appearance potentials of the dissociative electron-capture

4 Stevenson has shown that in the process $R_{1}-R_{2}+\mathrm{e} \rightarrow R_{1}++R_{2}+2 \mathrm{e}$ in $n$-and isoalkanes, for the equality $A\left(R_{1}^{+}\right)=D\left(R_{1}-R_{2}\right)+I\left(R_{1}\right)$ to hold, $I\left(R_{1}\right)<I\left(R_{2}\right)$.

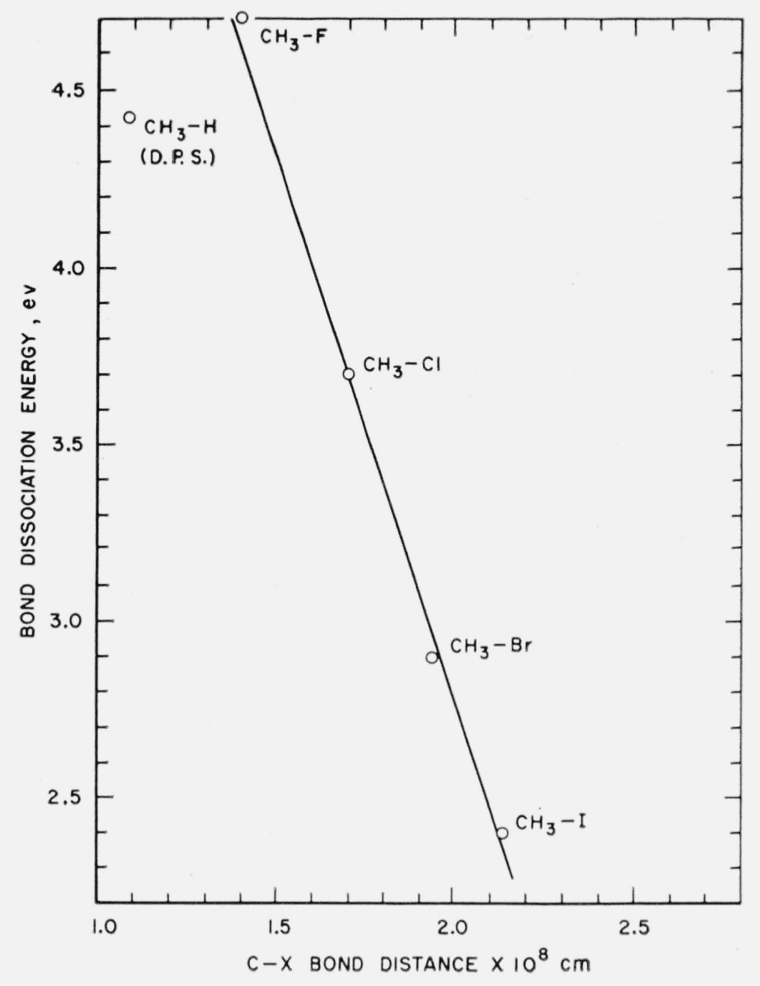

Figure 6. Plat of the carbon-halogen bond distance versus the observed values for the $\mathrm{C}-X$ bond-dissociation energy of the methyl halides.

ions, $\mathrm{Br}^{-}$and $\mathrm{I}^{-}$, is much greater than that for the ion-pair process ions, $\mathrm{F}^{-}$and $\mathrm{Cl}^{-}$. The very low energy required for electron capture is considerably below the ionizing-voltage calibration range. Furthermore, the rapid change in ionizing current with ionizing voltage makes difficult the measurement of relative abundances of these ions near the threshold potential. It is evident, however, that in the case of methyl bromide and methyl iodide, the $\mathrm{C}-X$ dissociation energies are equal to or less than the electron affinities of the bromine and iodine atoms.

In spite of the qualitative nature of the information of the dissociative electron-capture ions, the negative-ion studies give additional information on the electrical properties of the methyl halides. As a sharp distinction appears between the compounds in the matter of the electron-capture process, the behavior of the bromide and iodide molecules is expected to differ from that of the fluoride and chloride molecules when subjected to electric discharge or ionizing radiations.

The authors are indebted to Fred L. Mohler for helpful and stimulating discussions throughout the course of this work. The assistance of J. H. Lengel in the preparation of the methyl fluoride is also gratefully acknowledged. 


\section{References}

[1] S. Bauer and T. R. Hogness, J. Chem. Phys. 3, 687 (1935).

[2] J. D. Morrison and A. J. C. Nicholson, J. Chem. Phys. 20, 1021 (1952).

[3a] C. A. McDowell and B. G. Cox, J. Chem. Phys. 20, 1496 (1952).

[3b] C. A. MeDowell and B. G. Cox, J. Chem. Phys. 22, 946 (1954).

[4] H. Branson and C. Smith, J. Am. Chem. Soc. 75, 4133 (1953).

[5] W. C. Price, Phys. Rev. 47, 419 (1935); J. Chem. Phys. 4, 539 (1936).

[6] C. A. MeDowell and J. W. Warren, Discussions Faraday Soc. No. 10, 53 (1951).

[7] C. A. MeDowell and J. W. Warren, Trans. Faraday Soc. 48, 1084 (1952).

[8] F. L. Mohler, V. H. Dibeler, and R. M. Reese, J. Chem. Phys. 22, 394 (1954)

[9a] D. P. Stevenson and J. A. Hipple, J. Am. Chem. Soc. 64, 1588 (1942)

[9b] T. Mariner and W. Bleakney, Phys. Rev. 72, 807 (1947).

[9c] R. E. Honig, J. Chem. Phys. 16, 105 (1948).

[9d] J. J. Mitchell and F. F. Coleman, J. Chem. Phys. 17, 44 (1949).
[10] V. H. Dibeler, R. M. Reese, and F. L. Mohler, J. Chem Phys. 20, 761 (1952).

[11] H. D. Hagstrum, Rev. Mod. Phys. 23, 185 (1951).

[12] C. E. Moore, NBS Circular 467.

[13] H. O. Pritchard, Chem. Rev. 52, 529 (1953).

[14] F. P. Lossing, K. U. Ingold, and I. H. S. Henderson, J. Chem. Phys. 22, 621 (1954).

[15] R. S. Mulliken, Phys. Rev. 47, 413 (1935).

[16] J. P. Teegan and A. D. Walsh, J. Chem. Phys. 19, 1070 (1951).

[17] W. C. Price, Chem. Rev. 41, 257 (1947).

[18] G. Glockler, Fluorine chemistry, J. Simons, ed., p. 232, (Academic Press, Inc., New York, N. Y. 1950).

[19] F. P. Lossing, (private communication)..$^{5}$

[20] D. P. Stevenson, Trans. Faraday Soc. 49, 867 (1953).

[21] E. W. R. Steacie, Atomic and free radical reactions, (Reinhold Publishing Corp. N. Y. 1946).

[22] J. S. Roberts and H. A. Skinner, Trans. Faraday Soc. 45, 229 (1949).

5 After the present paper was written, F. P. Lossing, K. U. Ingold, and I. H. S. Henderson [J. Chem. Phys. 22, 1489 (1954)] published the results of a study of the methyl halides, including the results referred to above.

Washington, October 15, 1954. 